\title{
Sustainable Use of Natural Resources to Improve the Quality of Life in the Alto Palcazu Population Center, Iscozazin-Peru
}

\author{
Doris Esenarro, Ciro Rodriguez, Jennifer Arteaga, Godilia Garcia, and Fabiana Flores
}

\begin{abstract}
The present research aims at the sustainable use of natural resources in Iscozazin to improve the quality of life of its inhabitants. It proposes an architectural design of sustainable, productive housing that integrates agro-industry and ecotourism, which allows the optimization of the formative processes of sacha-inchi and cocoa with a growing export demand using clean energy in its production processes, minimizing the negative impacts on the environment. The methodology used was focused on three techniques "diagnosis", "adaptation," or "application" for the promotion of sustainable development. The analysis and export demand of existing products in the international market area were carried out. As a result, we have an architectural design proposal that respects the culture, customs, and climate of the place, allowing the excellent development and promotion of ecotourism and agro-industry. It also provides both residents and tourists with an option or recreational space focused on natural resources, presented in an orderly manner and preserving natural areas to generate a better activity flow without causing long-term damage.
\end{abstract}

Index Terms-Natural resources, quality of life, productive housing, export, clean energy, agroindustrial, Sacha inchi.

\section{INTRODUCTION}

Peru has 1933 native communities, of which 1270 are titled; of these, 98 are in Pasco's department. The Alto Iscozacin native community is located in the district of Palcazu in the province of Oxapampa.

The existing climatology in the area is fundamental for the development of its agricultural products. Several climates favor the growth of flora and fauna and, therefore, the conservation of its biodiversity.

This community has diverse natural, ecological, tourist, and cultural resources that revalue their territory. It belongs to the Yánesha ethnic group that previously "lived from hunting, fishing, and agriculture. Today, hunting is increasingly scarce, and agriculture has diversified, and they have begun to cultivate coffee and annatto and develop forestry activities. Handicrafts, especially ceramics, are also

Manuscript received October 9, 2020; revised March 5, 2021.

Doris Esenarro, Godilia Garcia, and Fabiana Flores are with the Faculty of Geographical, Environmental and Ecotourism Engineering, Federico Villarreal National University, Lima 1, Peru (e-mail: desenarro@unfv.edu.pe, ggarciav@unfv.edu.pe, 2015233717@unfv.edu.pe).

Ciro Rodriguez is with the Faculty of Computer and Electronic Engineering, Federico Villarreal National University, Lima 1, Peru (e-mail: crodriguez@unfv.edu.pe).

Jennifer Arteaga was with Faculty of International Business, Administration and International Business, Ciencias Aplicadas Peruvian University, Lima 1, Peru (e-mail: U20151C024@upc.edu.pe). a source of income". Alto Iscozacin has 119 men and 98 women with 217 inhabitants and a territorial extension of 2,660.18ha [1], [2].

Despite its rich landscape and culture, as well as the productivity of its lands in resources such as cocoa, coffee, Sacha Inchi, among others, the management of its territory is not being used in an adequate manner that allows for sustainable use; since various factors motivate the population to migrate, especially the people at an early age or young people, with the lack of workspaces with monetary compensation being one of the most prevalent [3].

Therefore, the purpose of this article is to design a productive rural housing proposal through the inclusion of ecotourism, architecture, and agro-industry as a tool to improve the necessary conditions of habitability and production, thus establishing an environment articulated with the functions and characteristics of the region and maintaining the cultural and social dynamics, which will allow benefits to the population and position it as a sustainable destination, since the proposed model seeks to have the minimum environmental impact.

The proposal will have as a priority to generate housing that supports the climatic conditions of these times and clean technologies, organic agriculture to protect the environment [4].

According to the Thornthwaite Climate Classification System, the Alto Iscozacin native community is located in the area that encompasses the climate $\mathrm{B}(\mathrm{r}) \mathrm{A}^{`} \mathrm{H} 4$ and $\mathrm{A}(\mathrm{r}) \mathrm{B}^{`} 1 \mathrm{H} 4$, thus considering

B(r)A`H4, Zone of warm, rainy climate, with abundant precipitations in all the year's stations, with relative humidity qualified as very humid.

A(r)B`1H4, Zone of stormy semi-warm climate, with abundant precipitations in all seasons of the year, with relative humidity qualified as very humid.

\section{METHOD}

\section{A. Location}

The topographic survey of the study location was carried out, as shown in Fig. 1, as well as the location of the geographies.

Fig. 1 shows the international location, accessibility, and study area; it also shows all its ecological environment.

Fig. 2 shows on the Meteorological Information, "average daily maximum" (continuous red line) means the average of the maximum temperature of one day for each month of Alto Iscozacín. Similarly, "average daily minimum" (straight blue 
line) means the minimum temperature average. Hot days and cold nights (dashed blue and red lines) show the standard of the hottest day and coldest night of each month for the last 30 years.

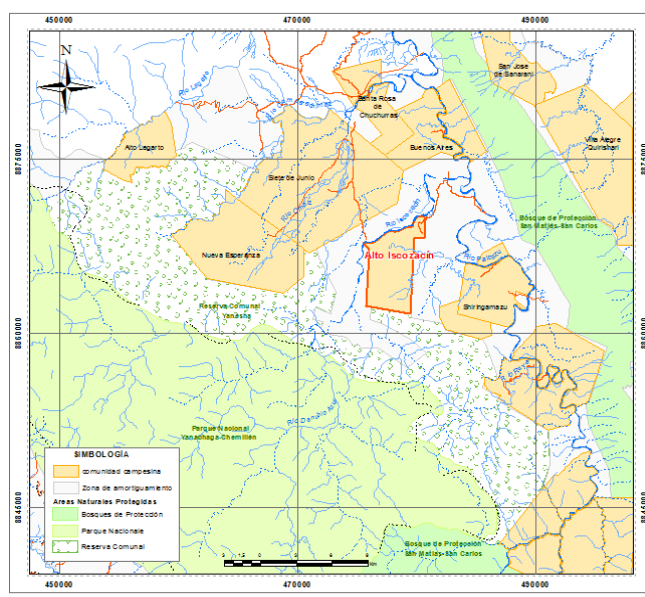

Fig. 1. Map of the proposal site.

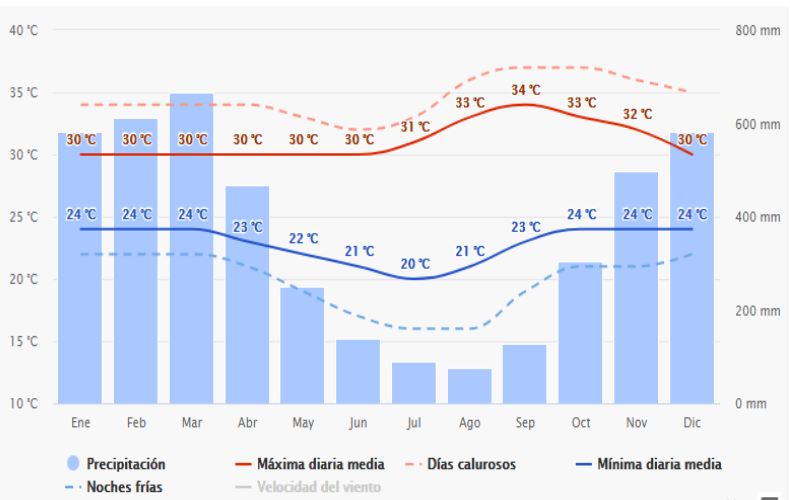

Fig. 2. Graph of average temperatures and rainfall Meteorology and climatology of the place.

\section{B. Method Employed}

The methodology that was considered for the achievement of our objectives. The graph assumes the steps taken straightforwardly and the general structure that the research follows. On the other hand, it can be seen that the project followed the diagnosis, adaptation, and application to reach the objective of sustainable development of natural resources in the selected area [5].

\section{Exports of Selected Products}

Tables I and II indicate the high participation and demand that the low countries have in exporting and importing the products. They are appreciated as the country that brings the highest income to exporters of Sacha Inchi and cocoa with \$447.05 $\mathrm{M}$ and \$2,167.58 M, respectively. The second place varies in both tables, but it is perceived that Netherlands and Germany have a fair share of the demand for both products. Thus, it is among the top 3 countries with the highest order, considering it a strong export market.

TABLE I: THE 5 COUNTRIES WITH THE HIGHEST DEMAND FOR SACHA INCHI

\begin{tabular}{|c|c|c|c|c|}
\hline $\mathbf{N}^{\circ}$ & Country & $\mathbf{\% V a r}$ & $\mathbf{\% P a r t}$ & Total(M\$) \\
\hline 1 & Netherlands & $5 \%$ & $25 \%$ & 477.05 \\
\hline 2 & Germany & $7 \%$ & $16 \%$ & 297.14 \\
\hline 3 & United Kingdom & $-39 \%$ & $13 \%$ & 413.14 \\
\hline 4 & Mexico & $-18 \%$ & $5 \%$ & 124.98 \\
\hline 5 & South Korea & $22 \%$ & $3 \%$ & 54.21 \\
\hline
\end{tabular}

TABLE II: THE 5 COUNTRIES WITH THE HIGHEST DEMAND FOR COCOA

\begin{tabular}{|c|c|c|c|c|}
\hline $\mathbf{N}^{\circ}$ & Country & $\%$ Var & $\%$ Part & $\begin{array}{c}\text { Total } \\
(\mathbf{M} \$)\end{array}$ \\
\hline 1 & Netherlands & $-23 \%$ & $21 \%$ & $2,167.58$ \\
\hline 2 & United States & $-30 \%$ & $13 \%$ & $1,468.13$ \\
\hline 3 & Germany & $-32 \%$ & $12 \%$ & $1,349.53$ \\
\hline 4 & Malaysia & $-13 \%$ & $11 \%$ & $1,007.55$ \\
\hline 5 & Belgium & $-17 \%$ & $7 \%$ & 723.55 \\
\hline
\end{tabular}

\section{RESULTS}

\section{A. Ecotourism}

Natural protected areas surround the location of our study area; these are Yanachaga Chemillen National Park, San Matías San Carlos Protected Forest, Yanesha Reserve; however tourism is currently an activity for which no resources are allocated, despite having forests and nature reserves, ideal for ecotourism.

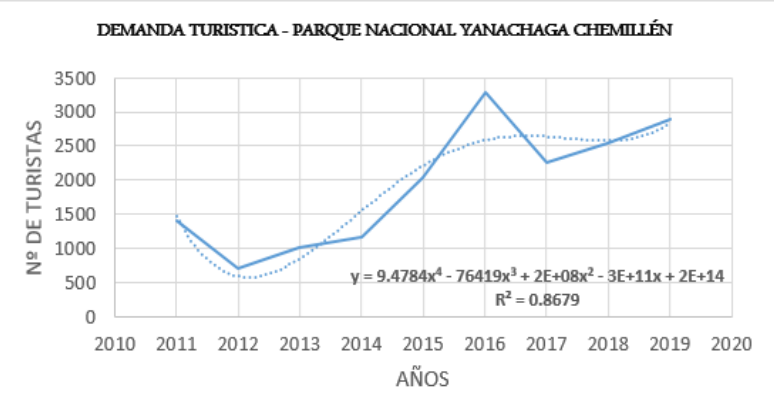

Fig. 3. Tourism demand.

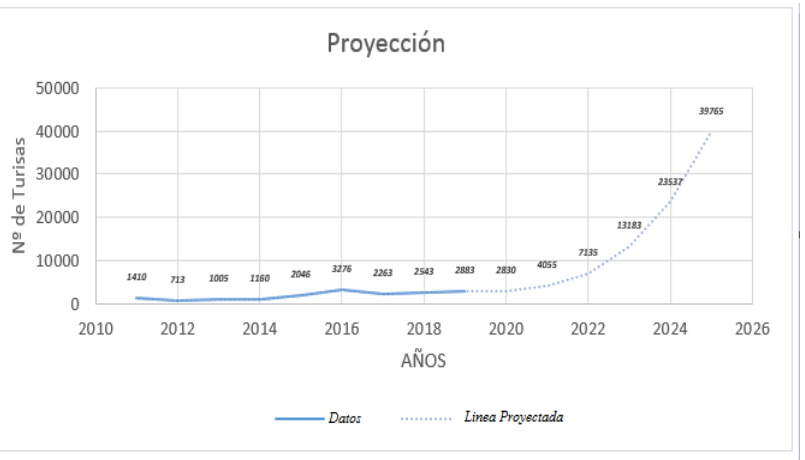

Fig. 4. Projection of tourism demand.

To determine the demand for income from potential ecotourists, as shows in Fig. 3 and 4, the flow of tourists into Yanachaga Chamillén Park was considered, since promoting tourism in the PNAs has become one of the best conservation strategies due to its low impact on the environment and for creating a multiplier effect on local economies, which is related to ecotourism [6].

\section{B. Architectural Proposal}

The architectural design proposal has the objective of developing all productive activities to export, which will allow them to generate economic income and generate sources of collective work. This proposal is also designed with a sustainable focus, using natural resources to comfort the users both in the house and in the productive process.

Table III and Fig. 5 prove the architectural distribution of the productive housing, as seen in the floor plan; it has hexagonal shapes for better spatial and climatic us. 
TABLE III: DETAILS OF THE ARCHITECTURAL PROPOSAL

\begin{tabular}{|c|c|c|c|c|c|c|}
\hline $\mathbf{1}$ & $\mathbf{2}$ & $\mathbf{3}$ & $\mathbf{4}$ & $\mathbf{5 , 6 , 7}$ & $\mathbf{8}$ & $\mathbf{9}$ \\
\hline Login & Rain & Bio- & Solid & Sowing & Gardeni & Processing \\
Collectors & digester & Collector & Area & ng & Area \\
\hline
\end{tabular}

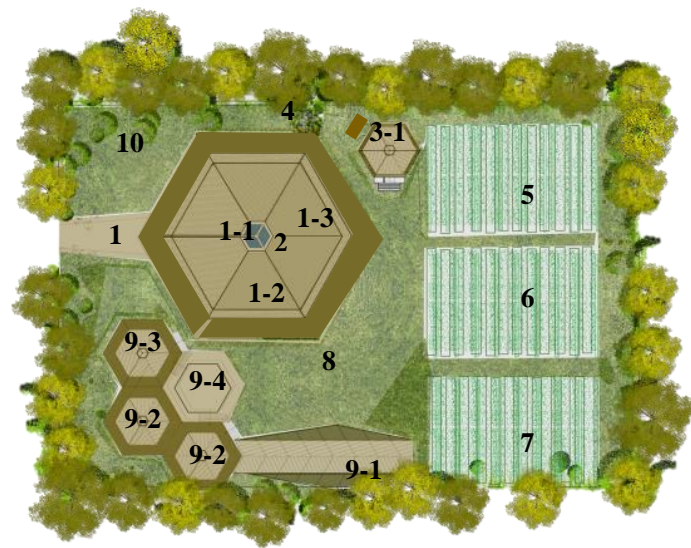

Fig. 5. Distribution of the architectural proposal.

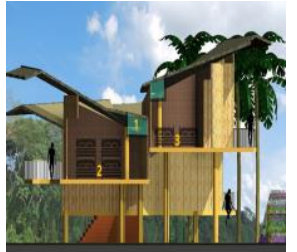

(a)

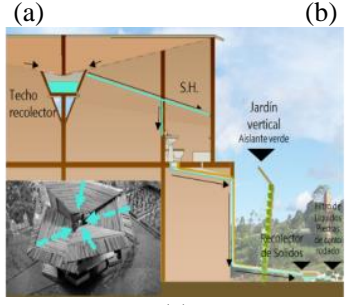

(c)

Fig. 6. Architectural characteristics of productive housing (a) and (b) clean technologies; rain collector (c).

Fig. 6 shows the characteristics of a productive dwelling. Here we detail the components of a place in which there is room to house a tourist family, as well as the capture of natural light, natural ventilation, a roof with a rain collector for use in the dwelling, the biodegradable raw materials of the area, the vertical garden and a solids collector for treatment through the local reeds [1], [3].
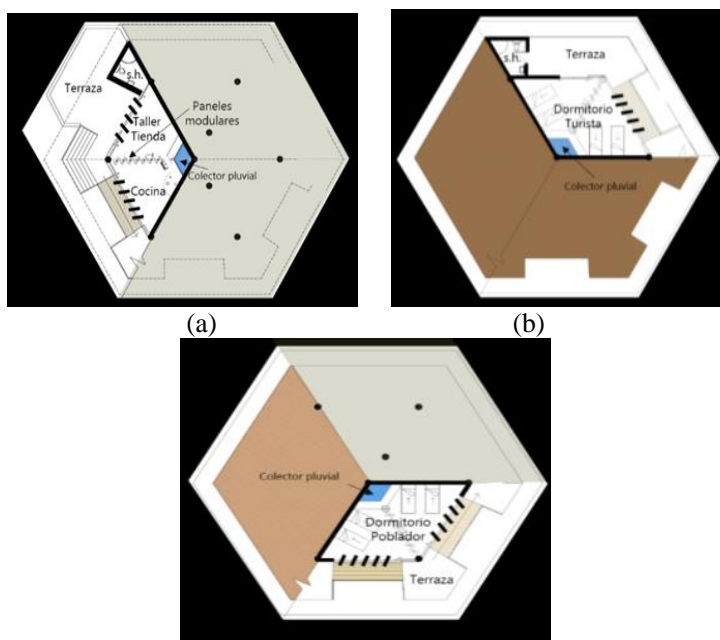

(c)

Fig. 7. The architectural layout of a productive house: (a), (b), and (c) front view of the design.
Fig. 7 displays the detail of the architectural design, where it is visualized, the creation of a hexagonal form, due to the perfect form of distribution, no loss of space, and what nature offers us honeycombs [7].

\section{Production and Export Processes of Cocoa and Sacha} Inchi

Foods such as cocoa and Sacha Inchi are products with robust social importance and involve the sustainable management of natural resources. These foods' properties increase their competitive level in the market, which is reflected in the growth of their demand through their exports worldwide. On the one hand, Cocoa is a caloric food that stands out for its high energy contribution. It comprises more than 50 nutrients (including fiber, vitamins, minerals, among others) and bio-actives (polyphenols). Likewise, the fruit is known for its blood pressure and cholesterol regulating benefits. On the other hand, Sacha Inchi is the richest in essential fats and beneficial to health. This is because its seeds contain a high omega 3, 6, and 9 fatty acids, which occupy approximately $93.6 \%$ of its composition. As some of its medicinal properties, it reduces the rate of triglycerides and improves blood circulation. Both foods benefit the population of other ages, especially older adults, and strengthen the immune system [8].

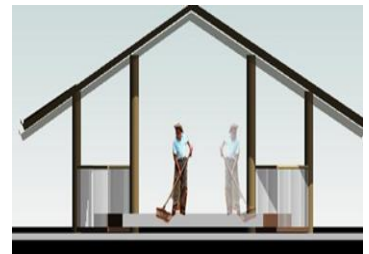

(a)

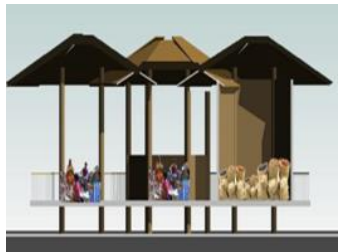

(b)

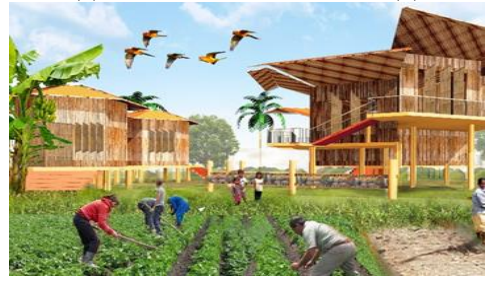

(c)

Fig. 8. Coca process (a), (b), (c).

Fig. 8 shows the production process of Sacha Inchi and cocoa, considering that they use sprinkler irrigation from the collection by water collector [8]; for their storage of the product, they do it in function to the FIFO method.

Cocoa Process. Cocoa is known to be a profitable product because it can produce several crops a year. Furthermore, being a perennial crop, it grows mainly in the rainforest brow area because of its humid climate [7].

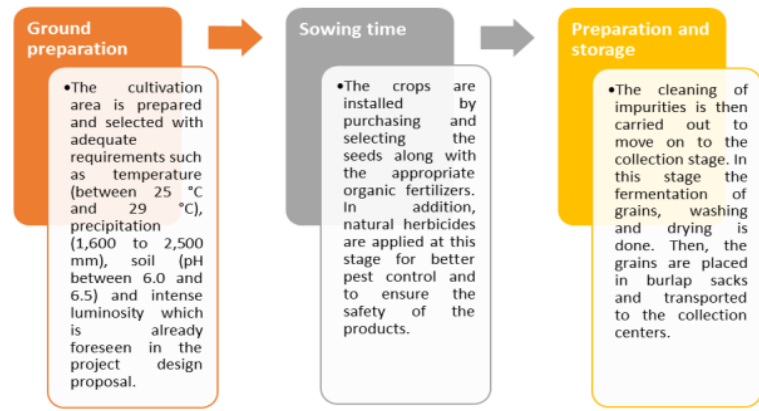

Fig. 9. Stages of the Cocoa process. 
For more details of the preparation and storage process stipulated in Fig. 9, in the stage of collection, it passes first through zone 9-1 indicated in Fig. 3, the drying of the fruits is carried out after its harvest. They are then taken to the process zone 9-2, selected for the cocoa product. The fermentation and drying of the beans are carried out evenly and divided into groups of equivalent weights. This facilitates weighing and distribution in burlap sacks, placed in the 9-3 storage area until they are transported [8].

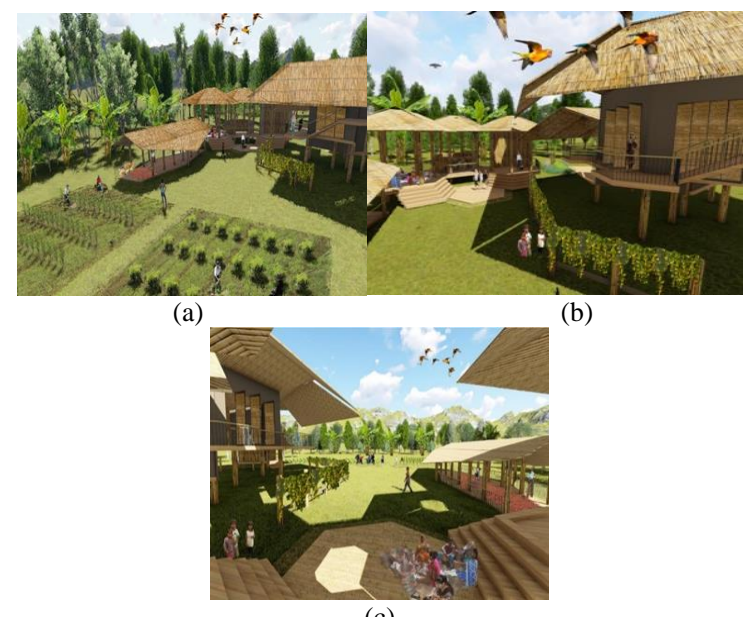

(c)

Fig. 10. Area of distribution of the productive zone (a) and (b) and of processes (c).

The environments shown in Fig. 10 have a design according to the sequence of production processes and seeks the comfort of users and tourist visitors [1], [3]; you can also see platforms' use.

Sacha Inchi process. The right product in the market, thanks to its high potential and performance provided by its components, has a growing demand in the industry. The Sacha Inchi production chain starts in an area located in the high jungle.

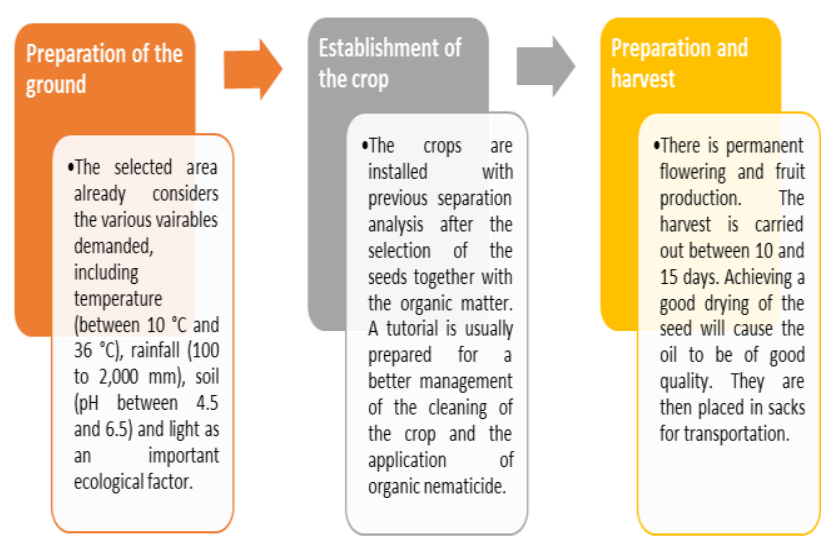

Fig. 11. Sacha Inchi process.

In the Sacha Inchi process, Fig. 11 shows in preparation and harvest that the 9-1 drying zone plays a significant role for the product. Achieving a good drying of the fruit will give it a more excellent added value in the market because it provides better quality. Next, in the process zone of the Sacha Inchi 9-2, a selection and division of weights is made to be placed in bags. These are taken to the last area 9-3, where they will be stored next to loads of cocoa waiting for their transfer, as shown in Fig. 9.

Table IV shows the project's projections over one year. This is separated by bimonthly income into five types of products or areas: guinea pig sales, the production and sale of Sacha Inchi and cocoa, room or space rental, and souvenir shop. Since this is a new project, the estimates of sales in some types are linear in a bimonthly manner in the first year of income projection. These will increase in a more differentiated way in future years depending on sales and visits. The only product that obtains sales in the last two quarters is guinea pigs. Because being an animal with high demand in the country, one has to wait to have an adequate supply (reproduction) to increase its quantity. Since the number of guinea pigs is estimated to be at the end of the year, it is possible to proceed with a bi-monthly increase in sales [9].

TABLE IV: INCOME PROJECTION

\begin{tabular}{|c|c|c|c|c|c|c|c|c|c|c|c|c|c|}
\hline & \multicolumn{2}{|c|}{ 1st bim } & \multicolumn{2}{|c|}{ 2nd bim } & \multicolumn{2}{|c|}{ 3rd bim } & \multicolumn{2}{|c|}{ 4th bim } & \multicolumn{2}{|c|}{ 5th bim } & \multicolumn{2}{|c|}{ 6th bim } & \multirow[b]{2}{*}{ Total (s/.) } \\
\hline Products & Qty & $\begin{array}{l}\text { Inc } \\
(\mathrm{s} / .)\end{array}$ & Qty & $\begin{array}{l}\text { Inc } \\
(\mathrm{s} / .)\end{array}$ & Qty & $\begin{array}{l}\text { Inc } \\
(\mathrm{s} / .)\end{array}$ & Qty & $\begin{array}{l}\text { Inc } \\
(\mathrm{s} / .)\end{array}$ & Qty & $\begin{array}{l}\text { Inc } \\
(\mathrm{s} / .)\end{array}$ & Qty & $\begin{array}{l}\text { Inc } \\
(\mathrm{s} / .) \\
\end{array}$ & \\
\hline Guinea Pigs & 10 & & 40 & & 100 & & 200 & & 400 & 200 & 500 & 400 & 600 \\
\hline Sacha Inchi/ Cocoa & 30 & 210 & 30 & 210 & 30 & 210 & 30 & 210 & 30 & 210 & 30 & 210 & 1260 \\
\hline Room & 2 & 200 & 2 & 200 & 2 & 200 & 2 & 200 & 2 & 200 & 2 & 200 & 1200 \\
\hline Souvenir Store & & 100 & & 100 & & 100 & & 100 & & 100 & & 100 & 600 \\
\hline Total & & 510 & & 510 & & 510 & & 510 & & 720 & & 9010 & 3660 \\
\hline
\end{tabular}

\section{CONCLUSION}

The responsible and sustainable use of natural resources allows for a better quality of life for the area's inhabitants and the conservation of biodiversity [3], [10].

The characteristics of the place propitiate a great variety of climatic biodiversity, variety of flora and fauna and allow the cultivation of high-quality products and great demand of exportable products in the international market, which allows the social and economic sustainability and the development of the population center [11], [12].

The use of clean energy, obtained from biodigesters (guinea pig breeding), rainwater capture, water collection through the collector, and solar radiation in its production processes, minimizes the impact on the environment [2], [13].

The selected export products provide nutrients and particular characteristics for the benefit of consumers. Even 
though they are not very well known in the international market, it is possible to have a growing demand for the product through techniques focused on bringing information to the user.

Also, the architectural project is focused and structured to provide benefits to both the local people and the area used. This is evident in the separations and the proposed order to achieve an adequate flow and take place's best possible advantage without causing long-term problems. [14].

\section{CONFLICT OF INTEREST}

The authors declare that we have no conflicts of interest.

\section{AUTHOR CONTRIBUTIONS}

Doris Esenarro carried out the research design; Doris Esenarro and Ciro Rodriguez analyzed the data; Doris Esenarro and Jennifer Arteaga carried out the design of the Doris Esenarro, Ciro Rodriguez, Jennifer Arteaga, and Godilia Garcia study area. We carried out the exploratory field study; the authors' contribution is reflected in all the research approved in its final version.

\section{REFERENCES}

[1] D. Esenarro, I. Escate, L. Anco, C. Tassara, and C. Rodriguez, "Proposal for an ecological research center for the recover y and revaluation of biodiversity in the town of Quichas-Lima, Peru," International Journal of Environmental Science and Development, vol. 11, no. 4, 2020.

[2] D. Esenarro, F. Cabello, P. Amaya, and C. Vargas, "Camping area and dock with viewpoint to promote sustainable ecotourist in the Ticcllacocha Lagoon, Tanta-Peru," International Journal of Environmental Science and Development, vol. 11, no. 51261, 2020.

[3] C. Rodriguez, D. Esenarro, P. Ccorimanya, F. Flores, C. Aylas, and J. Lagos, "Proposal for a sustainable infrastructure design (ecolodge) in the Quichas town, Perú,” Test Engeeniering \& Management, ISSN: 0193-4120, pp. 9250-9256, 2020.

[4] Earth Security Group (ESG). (2016). Indian insurance and sustainable development. Report by ESG, FICCI and British High Commission New Delhi. [Online]. Available: https://earthsecuritygroup.com/wp-content/uploads/2016/06/ESG.Indi aInsurance.pdf

[5] W. Quispe, D. Esenarro, C. Rodriguez, K. Alvarado, C. Ruiz, and W. Alvarez, "Physicochemical quality of honey bee (Apis mellifera) in three bioclimatic zones in Apurimac Perú," International Journal of Advanced Science and Technology, vol. 29, no. 7, pp. 268-275, 2020.

[6] W. Quispe, D. Esenarro, C. Rodriguez, M. Dolmos, R. Puerta, "Proposal system 'Queen Uruapana' design adapted to change climate, for the handling of queen bee (Apis mellifera) in Andahuaylas, Perú," Test Engeeniering \& Management, pp. 13442-13447, 2020.

[7] C. Bampatsou and G. Halkos, "Technical efficiency, productivity change and environmental degradation," MPRA Paper 77, University Library of Munich, Germany, 2017.

[8] C. Bampatsou and G. Halkos, "Investigating the effect of efficiency and technical changes on productivity," MPRA Paper 76287, University Library of Munich, Germany, 2016.

[9] World Health Organization (WHO). (2018). Household air pollution and health. World Health Organization. [Online]. Available: http://www.who.int/news-room/fact-sheets/detail/household-air-pollut ion-and-health

[10] D. Esenarro, C. Rodriguez, K. Huachaca, BetsyCachay, and C. Aylas, "Classification and characterization of the sustainable wetland bello horizonte," Test Engeeniering \& Management, pp. 13453-13458, 2020.

[11] E. Brown et al., "Low carbon energy and international development: From research impact to policymaking," Contemporary Social Science, vol. 13, no. 1, pp. 112-127, 2018.

[12] D. Esenarro, C. Rodriguez, C. Aquije, N. Obregon, L. Anicama, and C. Arguedas, "Cable car with water collection for afforestation of the solar hill in chorrillos, Perú," Test Engeeniering \& Management, pp. 9236-9242, 2020.

[13] United Nations. (2015). Transforming our world: The 2030 agenda for sustainable development. A/RES/70/1. [Online]. Available: https://sustainabledevelopment.un.org/content/documents/21252030\% 20Agenda\%20for\%20Sustaina

[14] FAO, IFAD, UNICEF, WFP \& WHO. (2017). The state of food security and nutrition in the world 2017: Building resilience for peace and food security. Rome: FAO. [Online]. Available: http://www.fao.org/state-of-food-security-nutrition/en/

Copyright $\odot 2021$ by the authors. This is an open access article distributed under the Creative Commons Attribution License which permits unrestricted use, distribution, and reproduction in any medium, provided the original work is properly cited (CC BY 4.0).

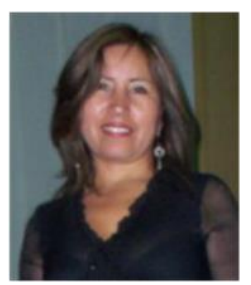

Doris Esenarro is a system engineer and she got the bachelor of the architecture of the National University Federico Villarreal, Lima, Peru. She is a professor of Faculty of Environmental Engineering of the University Federico Villarreal, professor of the Graduate School EUPG. Her contribution is Proposal of clean technologies for the project.

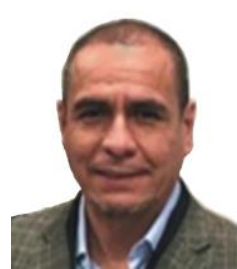

Ciro Rodriguez is an industrial engineer of the National University Federico Villarreal, Lima, Peru 1990. He is an associate professor of the Faculty of Computer and Electronic Engineering of the University Federico Villarreal, professor of the Graduate School EUPG, and the School of Software Engineering of the National University Mayor de San Marcos. His contribution is evaluation of the social, environmental, and economic viability of the project.

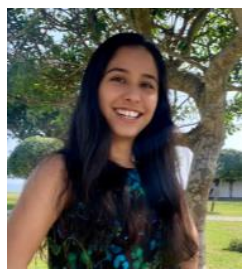

Jennifer Arteaga is with administration and international business of the Ciencias Aplicadas Peruvian University, Lima, Peru. She is a full-time senior student with knowledge in international trade management by the Peruvian export school ADEX. Her contribution is development of the proposal of the project.

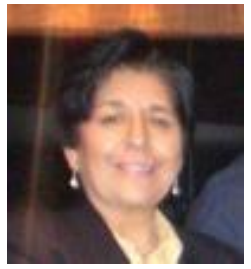

Godilia Garcia is a meteorological Engineer of the National University Federico Villarreal, Lima, Peru. She is a professor of Faculty of Environmental Engineering of the University Federico Villarreal. SENAMI worker in the area of meteorology, national service of climatology, and meteorology. Her contribution is development of the proposal of the project.

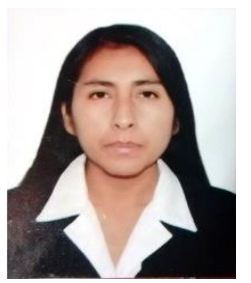

Fabiana Flores is an engineering in ecotourism of the National University Federico Villarreal, Lima, Peru. She got the bachelor of engineering in ecotourism from the University Federico Villarreal Her contribution is development of the proposal of the project. 